Arq. Bras. Med. Vet. Zootec., v.69, n.1, p.181-190, 2017

\title{
Desempenho produtivo de frangos de corte e utilização de energia e nutrientes de dietas iniciais com milho classificado ou não e suplementadas com complexo enzimático
}

\author{
[Broiler performance and energy and nutrient utilization of starter diets with classified corn or \\ not and supplemented with enzymatic complexes] \\ J.I.M. Fernandes, J.P. Contini, K. Prokoski, E.T. Gottardo, A.B. Cristo, R. Perini \\ Laboratório de Experimentação Avícola - Universidade Federal do Paraná - UFPR - Palotina, PR
}

\begin{abstract}
RESUMO
Dois experimentos foram conduzidos com o objetivo de avaliar o efeito da adição de um complexo enzimático em dietas iniciais elaboradas com milho classificado ou não por mesa densimétrica sobre o desempenho produtivo e a digestibilidade de nutrientes. Foram utilizados 1080 frangos de corte, machos, distribuídos em um delineamento inteiramente ao acaso, em esquema fatorial 2 × 3 (milho classificado ou não vs. dieta controle, dieta controle acrescida de complexo enzimático e dieta controle acrescida de enzimas e com redução de $150 \mathrm{kcal}$ de EM), totalizando seis repetições e 36 unidades experimentais. No ensaio de metabolismo, foram utilizadas 96 aves de 21 dias de idade, alojadas em baterias metálicas e distribuídas aos seis tratamentos, com oito repetições e 48 unidades experimentais. Dietas suplementadas com enzima, independentemente da classificação do milho, resultaram em maior $(\mathrm{P}<0,05)$ ganho de peso das aves aos 21 dias de idade. A adição de enzimas em dietas com milho classificado melhorou $(\mathrm{P}<0,05)$ a conversão alimentar. O CDPB foi maior $(\mathrm{P}<0,05)$ para dietas elaboradas com milho classificado, independentemente da suplementação do complexo enzimático, enquanto o CDEE de dietas à base de milho não classificado aumentou $(\mathrm{P}<0,05)$ quando as enzimas foram incluídas na deita. Dietas elaboradas à base de milho classificado e acrescidas de complexo enzimático comercial melhoraram $(\mathrm{P}<0,05)$ a EMA e a EMAn. As enzimas exógenas podem ser empregadas como ferramenta para melhorar a digestibilidade de nutrientes e de energia dos grãos de milho com variação nutricional.
\end{abstract}

Palavras-chave: energia metabolizável, PNAs, enzimas exógenas, ganho de peso

\begin{abstract}
Two experiments were performed with the aim of evaluating the effect of inclusion of enzymatic complexes in starter diets containing classified corn or not on the productive performance of poultry and nutrient digestibility. In the performance test 1080 broilers were used, distribuited in a completely randomized design in a factorial $2 \times 3$ (classified corn or not and corn control diet, control diet plus enzyme complex, and control diet plus enzymes and reduction of 150kcal of ME) and consisting of six replicates and 36 experimental units. In the metabolism trial 96 21-day-old birds were used, housed in metal cages, distributed to six treatments with eight replicates of 48 experimental units. Diets supplemented with enzyme, regardless of the corn classification, resulted in higher $(P<0.05)$ weight gain of birds at 21 days of age. The addition of enzymes in diets with classified corn improved $(P<0.05)$ feed conversion ratio. The $C D P B$ was higher $(P<0.05)$ for diets formulated with classified corn, regardless of the supplementation of the enzyme complex, while the CDEE of not classified corn-based diets increased $(P<0.05)$ when the enzymes were included. Diets formulated with classified corn plus commercial enzymatic complex, improved ( $P$ 0.05) the AME and AMEn. Exogenous enzymes may be employed as a tool to improve the digestibility of nutrients and energy of corn with nutritional variation.
\end{abstract}

Keywords: metabolizable energy, NAPs, exogenous enzymes, amylase, weight gain

Recebido em 8 de março de 2015

Aceito em 9 de agosto de 2016

E-mail: jimfernandes@ufpr.br 


\section{Fernandes et al.}

\section{INTRODUÇÃO}

O milho, por possuir grande quantidade de carboidratos e lipídios, é o principal ingrediente utilizado nas formulações de rações de suínos e aves, compondo cerca de $60 \%$ da ração inicial de frangos de corte e aproximadamente $65 \%$ da energia metabolizável (Rufatto et al., 2000).

Ainda que as dietas à base de milho não interfiram na viscosidade no trato digestório, existe um interesse considerável em identificar condições em que a adição de enzimas nessas dietas seja vantajosa. Estima-se que cerca de 400 a $450 \mathrm{kcal}$ de energia por $\mathrm{kg}$ de dieta não sejam aproveitados quando as aves são alimentadas com uma ração à base de milho e soja (Cowieson et al., 2010). Estratégias que permitam o melhor aproveitamento do conteúdo energético dos alimentos e a redução dos custos devem ser amplamente estudadas (Costa et al., 2004).

Dessa forma, as enzimas exógenas podem ser empregadas como ferramenta para melhorar a digestibilidade de nutrientes e de energia dos grãos de milho (Aguilar et al., 2007), pois, embora o milho possua baixo conteúdo em fibra quando comparado com outros ingredientes (Rostagno et al., 2011), possui frações de polissacarídeos não amiláceos (PNAs). A adição de enzimas que degradam polissacarídeos pode liberar o amido encapsulado, por solubilização da parede celular, melhorando o acesso de enzimas digestivas e a disponibilidade dos nutrientes (Slominski, 2011).

Grãos de má qualidade podem ter seu valor nutricional comprometido pela alteração da composição química, como consequência da diminuição da biodisponibilidade de alguns nutrientes e/ou proliferação de fungos com ou sem produção de micotoxinas (Mazzuco et al., 2002).

Segundo Baidoo et al. (1991), o decréscimo de $20 \%$ na densidade do grão reduz cerca de $4,3 \%$ o valor da EMA (energia metabolizável aparente). Assim, ao se compararem milhos de densidades diferentes mediante o uso de mesa densimétrica, observa-se que milhos com densidade inferior apresentam menores níveis de EMA.

As respostas ao uso de enzimas como carboidrases e proteases em dietas para aves são pouco consolidadas quando comparadas com a utilização da fitase, que apresenta diversos efeitos positivos e respostas bastante conclusivas, principalmente em dietas à base de milho e farelo de soja (Cowieson e Adeola, 2005). A ausência de benefícios ao uso de enzimas exógenas, ou complexos enzimáticos, ou mesmo a inconsistência dos resultados, pode ser causada por fatores como valorização nutricional incorreta da enzima utilizada e principalmente pela qualidade e composição dos ingredientes utilizados na dieta (Sorbara et al., 2009).

O preço do milho apresenta grande variação ao longo do ano, sendo maior principalmente nas entressafras, gerando, assim, oportunidade para intensificação da utilização de complexos enzimáticos.

O objetivo do trabalho foi avaliar o efeito da adição de um complexo enzimático em dietas formuladas com milho classificado ou não por mesa densimétrica, sobre o desempenho produtivo e a digestibilidade de nutrientes.

\section{MATERIAL E MÉTODOS}

A pesquisa foi desenvolvida por meio de dois ensaios (desempenho e metabolismo), os quais foram conduzidos no aviário experimental da Universidade Federal do Paraná - Setor Palotina (número do protocolo de aprovação do Comitê de Ética: 01/2014).

No experimento I, foram utilizadas 1080 aves de corte, machos, da linhagem Cobb Slow, provenientes de matrizes de 35 semanas. No alojamento, as aves foram alocadas em um delineamento inteiramente ao acaso, em esquema fatorial $2 \times 3$ (milho classificado ou não e dieta controle, dieta controle acrescida de complexo enzimático e dieta controle acrescida de enzimas e com redução de $150 \mathrm{kcal}$ de $\mathrm{EM})$ e seis repetições, totalizando 36 unidades experimentais.

As aves foram mantidas em temperatura de conforto térmico, de acordo com sua fase de vida. Ração e água foram fornecidas à vontade. As rações experimentais foram fornecidas até os 21 dias, e até o final do período experimental, foi fornecida ração comercial para todas as aves. 
Antes da elaboração das dietas experimentais, foram coletadas amostras dos milhos classificado e não classificado, para determinar os níveis de micotoxinas presentes. Para classificar o milho, foi utilizada uma mesa densimétrica comercial da empresa fornecedora dos ingredientes. A suplementação de enzimas foi feita pela adição de um complexo enzimático comercial constituído de amilase, protease e xilanase.

Aos sete e aos 21 dias, foram pesadas as aves e as sobras de ração de cada unidade experimental para a determinação do ganho de peso corporal, consumo de ração e conversão alimentar. Aos 21 dias de idade, duas aves por repetição (12 aves/tratamento) foram sacrificadas por deslocamento cervical. Após o sacrifício, as aves foram pesadas individualmente, e as carcaças dessecadas para remoção da moela, próventrículo, pâncreas, fígado e intestino delgado, que, em seguida, foram pesados. $\mathrm{O}$ peso relativo de cada órgão foi obtido pela fórmula: peso relativo $=($ peso órgão/peso vivo $) \times 100$.

Foram obtidos fragmentos de aproximadamente $5 \mathrm{~cm}$ de comprimento do duodeno e do jejuno, fixados em formol para análise histológica. Os cortes foram capturados e analisados utilizandose Image Pro-Plus - versão 5.2 - média cibernética. Foi mensurada a altura de 20 vilos e a profundidade de 20 criptas de cada repetição por segmento, e destes valores foi obtida a média.

Tabela 1. Composição percentual e calculada das dietas experimentais dos frangos de corte no período inicial de um a 21 dias

\begin{tabular}{lcc}
\hline Ingrediente (\%) & Ração controle & Ração com redução de EM \\
\hline Milho & 54,665 & 57,280 \\
Farelo de soja & 37,700 & 37,500 \\
Óleo de soja & 3,400 & 0,700 \\
Calcário & 1,030 & 1,272 \\
Fosfato bicálcico & 1,950 & 1,950 \\
Sal comum & 0,285 & 0,280 \\
Bicarbonato de sódio & 0,240 & 0,245 \\
DL-metionina 98\% & 0,336 & 0,332 \\
L-lisina HCl 78\% & 0,220 & 0,220 \\
L-treonina 98\% & 0,084 & 0,082 \\
Colina 60\% & 0,090 & 0,089 \\
Complexo enzimático comercial ${ }^{1}$ & - & 0,050 \\
Premix vitamínico e mineral ${ }^{2,3}$ & 0,100 & 0,100 \\
\hline Valor calculado & 100 & 100 \\
\hline Proteínabruta, \% & 21,84 & 21,95 \\
Energia metabolizável, kcal/kg & 2.970 & 2.820 \\
Cálcio, \% & 0,941 & 1,033 \\
Fósforo disponível, \% & 0,481 & 0,483 \\
Lisina digestível., \% & 1,241 & 1,241 \\
AAST digestível, \% & 0,919 & 0,920 \\
Treonina digestível, \% & 0,800 & 0,801 \\
Arginina digestível, \% & 1,349 & 1,351 \\
Colina, \% & 1,796 & 1,800 \\
BED ${ }^{4}$ mEq/100g & 254,29 & 255,86 \\
\hline Adiça 0 \% & &
\end{tabular}

${ }^{1}$ Adição de $0,050 \%$ na dieta controle + complexo enzimático comercial

${ }^{2}$ Mistura vitamínica (conteúdo por $\mathrm{kg}$ de premix): vit. A 7.000.000,00UI; vit. D3 2.200.000,00UI; vit. K3 $1.600,00 \mathrm{mg}$; vit. B1 2.000,00mg; vit. B2 5.000,00mg; vit. B12 12.000,00mg; niacina 35.000,00mg; ácido pantotênico $13.000,00 \mathrm{mg}$; ácido fólico $800,00 \mathrm{mg}$; antioxidante $100.000,00$; veículo q.s.p. $1.000,00 \mathrm{~g}$.

${ }^{3}$ Mistura mineral (conteúdo por $\mathrm{kg}$ de premix): ferro $10.000,00 \mathrm{mg}$; cobre $16.000,00 \mathrm{mg}$; iodo 2.400,00mg; zinco $100.000,00 \mathrm{mg}$; manganês $140.000,00 \mathrm{mg}$; selênio $400,00 \mathrm{mg}$; veículo q.s.p. $1.000,00 \mathrm{~g}$.

${ }^{4}$ Balanço eletrolítico da dieta (Mongin, 1981): $B E D=\left[\left(\begin{array}{lll}\% & N a * 10.000 / 22,990)+(\% & K * 10.000 / 39,102\end{array}\right)\right]-(\%$ $\left.\mathrm{Cl}^{*} 10.000 / 35,453\right)$. 
No ensaio de metabolismo, foram utilizadas 96 aves de 21 dias de idade, provenientes do experimento I, as quais foram distribuídas aos seis tratamentos com oito repetições, totalizando 48 unidades experimentais. Foram utilizadas quatro baterias, com 12 gaiolas cada.

Foi empregado o método de coleta total de excretas, com período experimental de sete dias, sendo oito de adaptação e cinco de coleta das excretas. As excretas coletadas diariamente foram pesadas e armazenadas a -20C. Após o término do período de coleta, as amostras de excretas e das dietas experimentais foram analisadas para o conteúdo de matéria seca, extrato etéreo, energia bruta e nitrogênio, conforme técnicas descritas por AOAC (Official..., 1995).

Os teores de energia bruta foram determinados em bomba calorimétrica adiabática. Com base nos dados de consumo de dieta, de produção de excretas e dos resultados das análises de laboratório, procedeu-se ao cálculo dos coeficientes de digestibilidade da proteína bruta (CDPB), da matéria seca (CDMS) e do extrato etéreo (CDEE), bem como dos valores de energia metabolizável aparente (EMA) e de aparente corrigida (EMAn), utilizando-se as equações propostas por Matterson et al. (1965).

Os dados foram submetidos à análise de variância por meio do procedimento GLM do programa estatístico SAS (SAS Institute Inc., 2002) para um modelo fatorial e, em caso de significância, as médias referentes às dietas foram comparadas pelo teste de Tukey a $5 \%$ de probabilidade.

\section{RESULTADOS E DISCUSSÃO}

O milho não classificado apresentou maiores níveis de aflatoxina e zearalenona em relação ao milho classificado. Esses resultados das análises de micotoxinas no milho classificado ou não, utilizado na elaboração das rações experimentais, estão apresentados na Tab. 2. Segundo Mallmann et al. (2009), as micotoxinas de maior importância para a produção avícola no Brasil são as aflatoxinas, seguidas pelas fumonisinas e o deoxinivalenol.

Os resultados referentes ao desempenho produtivo das aves que receberam dietas formuladas com milhos de diferentes densidades, com a adição de enzimas ou não e com a redução de energia, são apresentados na Tab. 3. Não houve interação significativa $(\mathrm{P}>0,05)$ entre os fatores principais para o desempenho produtivo, com exceção da conversão alimentar de um a 21 dias.

Tabela 2. Composição micotoxicológica dos grãos de milho utilizados nas formulações das dietas experimentais

\begin{tabular}{ccc}
\hline $\begin{array}{c}\text { Zearalenona } \\
(\mathrm{ppb})\end{array}$ & $\begin{array}{c}\text { Milho } \\
\text { classificado }\end{array}$ & $\begin{array}{c}\text { Milho não } \\
\text { classificado }\end{array}$ \\
\cline { 2 - 3 } & 88 & 160 \\
\hline $\begin{array}{c}\text { Fumonisina } \\
(\mathrm{ppm})\end{array}$ & $<20$ & $<20$ \\
$\begin{array}{c}\text { Aflotoxina } \\
(\mathrm{ppb})\end{array}$ & 3,8 & 13 \\
\hline
\end{tabular}

No período de um a sete dias, houve efeito significativo $(\mathrm{P}<0,05)$ da classificação do milho. Aves que receberam dieta com milho classificado apresentaram menor consumo de ração e melhor conversão alimentar, independentemente da adição ou não de enzimas. A densidade dos grãos de milho tem correlação positiva com o nível energético (Silva et al., 2008). A energia é um dos fatores que interferem no consumo de alimento pelo animal; aves que receberam a dieta com milho classificado apresentaram menor consumo e, consequentemente, uma melhor conversão alimentar. $\mathrm{O}$ milho é um cereal facilmente atacado por pragas que alteram sua composição química e, em consequência, seu valor nutritivo (Meronuck, 1987).

Além da contaminação fúngica, níveis elevados de micotoxinas no milho não selecionado, utilizado neste experimento, podem também ter contribuído para o pior desempenho de aves. Conforme observado na Tab. 1 , o resultado das análises para detecção de micotoxinas de amostras do milho classificado e não classificado mostra níveis maiores para o milho não classificado. Silva et al. (2008) verificaram um crescente aumento, tanto de aflatoxinas quanto de tricotecenos, à medida que a qualidade do milho piora, expressa pela classificação e pela densidade. Segundo Zaviezo e Contreras (2005), a contaminação por micotoxinas promove redução de 4 a $5 \%$ do valor da energia metabolizável. 
Tabela 3. Desempenho produtivo de frangos de corte recebendo dietas elaboradas com milho classificado ou não e suplementadas ou não com enzima em dietas com redução ou não da energia metabolizável

\begin{tabular}{|c|c|c|c|c|c|c|c|c|c|}
\hline & \multicolumn{3}{|c|}{ Ganho de peso, $\mathrm{g}$} & \multicolumn{3}{|c|}{ Consumo de ração, $g$} & \multicolumn{3}{|c|}{ Conversão alimentar } \\
\hline & \multicolumn{9}{|c|}{1 a 7 dias } \\
\hline & $\mathrm{MC}$ & MNC & Média & $\mathrm{MC}$ & $\mathrm{MNC}$ & Média & $\mathrm{MC}$ & MNC & Média \\
\hline Controle & 141,4 & 140,4 & 140,91 & 174,1 & 178,3 & 176,2 & 1,23 & 1,27 & 1,25 \\
\hline $\mathrm{CE}$ & 146,4 & 145,2 & 145,89 & 173,6 & 192,1 & 182,8 & 1,19 & 1,32 & 1,25 \\
\hline $\mathrm{CE} \downarrow \mathrm{EM}$ & 137,8 & 137,8 & 137,82 & 177,6 & 184,5 & 181,1 & 1,29 & 1,34 & 1,31 \\
\hline Média & 141,8 & 141,2 & & $175,1^{\mathrm{b}}$ & $184,9^{\mathrm{a}}$ & & $1,2^{\mathrm{a}}$ & $1,31^{\mathrm{b}}$ & \\
\hline Interação & & NS & & & NS & & & NS & \\
\hline $\mathrm{CV}, \%$ & \multicolumn{6}{|c|}{$\begin{array}{c}5,97 \\
21 \text { dias }\end{array}$} & & 6,35 & \\
\hline Controle & 953,7 & 932,6 & $943,16^{\mathrm{B}}$ & 1271,9 & 1293,1 & $1282,7^{\mathrm{B}}$ & $1,33^{\mathrm{aB}}$ & $1,39^{\mathrm{aA}}$ & 1,36 \\
\hline $\mathrm{CE}$ & 992,9 & 960,2 & $976,58^{\mathrm{A}}$ & 1293,1 & 1348,2 & $1320,6^{\mathrm{A}}$ & $1,33^{\mathrm{bB}}$ & $1,40^{\mathrm{aA}}$ & 1,35 \\
\hline $\mathrm{CE} \downarrow \mathrm{EM}$ & 902,6 & 912,4 & $907,49^{\mathrm{C}}$ & 1304,8 & 1312,6 & $1308,7^{\mathrm{AB}}$ & $1,44^{\mathrm{aA}}$ & $1,44^{\mathrm{aA}}$ & 1,44 \\
\hline Média & 949,7 & 935,1 & & $1289,9^{\mathrm{b}}$ & $1318,1^{\mathrm{a}}$ & & 1,36 & 1,41 & \\
\hline Interação & & NS & & & NS & & & $\mathrm{P}<0,05$ & \\
\hline \multirow[t]{2}{*}{$\mathrm{CV}, \%$} & \multirow{2}{*}{\multicolumn{6}{|c|}{1 a 42 dias }} & & 3,42 & \\
\hline & & & & & & & & & \\
\hline Controle & 3144,9 & 3102,8 & $3123,8^{\mathrm{a}}$ & 4102,5 & 4131,9 & 4117,2 & 1,67 & 1,65 & 1,66 \\
\hline CE & 3132,7 & 3104,0 & $3118,3^{\mathrm{a}}$ & 4217,2 & 4243,0 & 4230,1 & 1,66 & 1,71 & 1,68 \\
\hline $\mathrm{CE} \downarrow \mathrm{EM}$ & 3013,0 & 2981,8 & $2997,4^{\mathrm{b}}$ & 4195,7 & 4209,7 & 4202,7 & 1,71 & 1,72 & 1,71 \\
\hline Média & 3096,8 & 3062,9 & & 4171,8 & 4194,9 & & & & \\
\hline Interação & & NS & & & NS & & & NS & \\
\hline CV,$\%$ & & 2,72 & & & 2,92 & & & 3,10 & \\
\hline
\end{tabular}

CE: complexo enzimático, CE $\downarrow$ EM: complexo enzimático + redução de 150kcal de EM, MC: milho classificado, MNC: milho não classificado. *Médias seguidas de letras distintas minúsculas na linha diferem entre si pelo teste de Tukey. Médias seguidas de letras maiúsculas distintas na coluna diferem entre si pelo teste de Tukey.

Para o fator enzimas, não foram encontrados resultados significativos $(\mathrm{P}>0,05)$ na fase inicial de um a sete dias. Para o período total de um a 21 dias, as aves suplementadas com enzima, independentemente da classificação do milho, apresentaram maior ganho de peso $(\mathrm{P}<0,05)$. $\mathrm{O}$ consumo de ração foi maior $(\mathrm{P}<0,05)$ para as aves que receberam dieta elaborada com milho não classificado, enquanto a adição de enzima na dieta controle levou a um maior $(\mathrm{P}<0,05)$ consumo de ração quando este foi comparado ao consumo da dieta controle.

Para a conversão alimentar, houve interação significativa $(\mathrm{P}<0,05)$ entre enzimas $\mathrm{e}$ classificação do milho. No desdobramento da interação, observou-se que o uso de dietas elaboradas com milho classificado e com redução da energia piorou a conversão aliomentar das aves $(\mathrm{P}<0,05)$ em relação à dieta controle e à dieta acrescida de enzima. Já para as dietas elaboradas com milho não classificado, não foi observado efeito significativo $(\mathrm{P}<0,05)$ da adição de enzimas. Comparando-se a adição de enzimas em dietas elaboradas com milho classificado e não classificado, o melhor resultado para conversão alimentar $(\mathrm{P}<0,05)$ foi obtido quando se associaram enzimas ao milho classificado. $\mathrm{O}$ uso de enzimas em dietas com redução de energia e independentemente da classificação do milho não foi suficiente para melhorar o desempenho das aves.

Complexos enzimáticos melhoraram o desempenho produtivo de frangos de corte quando adicionados a dietas milho-soja (Zanella et al., 1999; Yu e Chung, 2004; Cowieson e Adeola, 2005). Por outro lado, Costa Leite et al. (2011) observaram efeito do complexo enzimático apenas sobre a conversão alimentar. É importante considerar a variação nutricional e das frações de PNAs no milho e no sorgo. Malathi e Devegowda (2001) encontraram 9 e $29 \%$ de fatores antinutricionais na forma de polissacarídeos não amídicos no milho e no sorgo, respectivamente. Da mesma forma, Rodrigues et al. (2003), ao adicionarem um complexo enzimático, não encontraram alteração 
no desempenho médio das aves no período de 15 a 27 dias. Entretanto, estes autores utilizaram uma dieta com ingredientes alternativos, com alto teor de fibra e elevada concentração de PNAs.

Enzimas exógenas atuam sobre substratos específicos, por isso é necessário um maior entendimento sobre a presença, a quantidade e a composição dos diferentes PNAs nos ingredientes para que o uso dessas ferramentas resulte em maiores ganhos no desempenho produtivo e na otimização dos custos de produção.

Strada et al. (2005) adicionaram complexo enzimático a dietas com valores superestimados em $9 \%$ para EM e obtiveram resultados semelhantes ao uso da dieta controle. Os autores concluíram que a inclusão de enzimas nas dietas com redução da densidade energética não comprometeu o desempenho de frangos de corte, devido à maior liberação e utilização da energia.

Os tratamentos foram fornecidos até os 21 dias, e aos 42 dias de idade pode ainda ser observado o reflexo negativo $(\mathrm{P}<0,05)$ da redução de energia, independentemente da inclusão de enzima e da classificação do milho sobre o ganho de peso das aves (Tab. 3).

Em todo o período estudado, o uso de milho classificado, independentemente do uso de enzimas, melhorou o desempenho inicial das aves, levando também a um menor consumo de ração no período de um a 21 dias. A média de custo por kg e o custo por ave, durante o período de um a 21 dias, e de 22 a 42 dias, foram menores para a dieta composta por milho não classificado. Com a utilização do milho não classificado, houve uma redução de 7,$1 ; 6,81$ e $6,92 \%$ no custo $/ \mathrm{kg}$ de frango de um a 21,22 a 42 e um a 42 dias, respectivamente (Tab. 4).

Rodrigues et al. (2003) avaliaram milho de diferentes variedades e com variação na composição bromatológica e observaram melhor ganho de peso e conversão alimentar de acordo com a densidade de nutrientes presentes nas variedades.

Lima (2005) enfatiza que a utilização de enzimas em dietas à base de milho e soja na alimentação de aves visa reduzir os fatores antinutricionais, aumentando a disponibilidade dos nutrientes encapsulados dentro da parede celular ou ligados em uma estrutura química que o animal é incapaz de digerir. Ao et al. (2009) mencionam ainda que a suplementação de enzimas pode beneficiar pintos de corte por meio da melhoria da energia das dietas, haja vista a variabilidade na composição nutricional do milho.

Houve efeito significativo $(\mathrm{P}<0,05)$ das dietas sobre o peso relativo da moela, do pró-ventrículo e do fígado, independentemente do tipo de milho utilizado (Tab. 5). A inclusão de enzima às dietas levou ao menor peso relativo da moela em comparação à dieta controle. As enzimas digestivas exógenas atuam rompendo paredes celulares e degradando nutrientes, o que pode ter contribuído para a redução da atividade mecânica da moela. Por outro lado, o peso relativo do pâncreas foi maior nas aves que receberam enzimas na dieta. A maior e mais rápida degradação dos nutrientes pela ação de enzimas exógenas pode ter estimulado a secreção pancreática, o que resultou em maior peso relativo. Já o aumento do peso do fígado observado nas dietas suplementadas com enzimas em relação à dieta controle pode ser atribuído à maior demanda metabólica, visto que as aves destes tratamentos apresentaram maior ganho de peso. Apenas o peso relativo do próventrículo foi afetado pelo tipo de milho. Dietas elaboradas com milho de má qualidade resultaram em maiores valores $(\mathrm{P}<0,05)$ de peso relativo do pró-ventrículo.

A morfometria intestinal realizada aos 21 dias não mostrou diferença estatística $(\mathrm{P}<0,05)$ para nenhuma característica avaliada (Tab. 6).

Dietas à base de milho e soja são pouco agressivas à mucosa intestinal. A presença de fragmentos não digeridos contribui negativamente para o estado inflamatório da mucosa entérica. A ingestão de ingredientes ricos em PNA provoca apoptose epitelial ao longo dos vilos e das criptas, fusão de vilos, bem como aumento em número e alargamento citoplasmático de células caliciformes, produzindo espessamento da camada de muco do revestimento epitelial da mucosa intestinal (Slominski, 2011; AO et al., 2009).

Os resultados referentes ao ensaio de metabolismo, coeficientes de digestibilidade da 
matéria seca (CDMS), da proteína bruta (CDPB) e do extrato etéreo (CDEE), estão apresentados na Tab. 7. Não houve efeito $(P>0,05)$ da adição de enzima ou da classificação do milho sobre o CDMS. Observou-se efeito significativo $(\mathrm{P}<0,05)$ apenas para o tipo de milho utilizado na elaboração das dietas sobre o $\mathrm{CDPB}$, com o maior coeficiente de digestibilidade para dietas com milho classificado. Houve interação significativa $(\mathrm{P}<0,05)$ entre o fator classificação do milho e as dietas para o CDEE. Ao se desdobrar a interação, observou-se que, para o milho classificado, a utilização de enzima ou a redução da EM não influenciou o CDEE. Já para dietas elaboradas com milho não classificado, o menor coeficiente de digestibilidade foi observado em dietas com redução de energia e uso de enzimas. Na comparação entre milho classificado ou não, observou-se que dietas elaboradas com milho classificado sem enzima e com redução da EM apresentaram um maior CDEE do que com milho não classificado. Entretanto, quando houve a adição de enzimas à dieta elaborada com milho não classificado, o CDEE foi similar. Este resultado implica que é possível o melhor aproveitamento da gordura de grãos de milho de pior qualidade quando são adicionados complexos enzimáticos.

Os resultados referentes aos valores de energia metabolizável aparente (EMA) e de energia metabolizável aparente corrigida para balanço de nitrogênio (EMAn) são apresentados na Tab. 8. Houve interação significativa $(\mathrm{P}<0,05)$ entre $\mathrm{o}$ fator classificação do milho e a suplementação enzimática para a EMA. Ao se desdobrar a interação, observou-se que, para o milho classificado, houve um maior valor de EMA para dietas suplementadas com enzimas em comparação às demais.

A dieta com redução de EM, apesar de suplementada com enzima, apresentou o menor valor de EMA. Para as dietas elaboradas com milho não classificado, não houve diferença significativa $(\mathrm{P}>0,05)$ para a EMA. Comparando-se as dietas elaboradas com milho classificado ou não, observou-se que a suplementação com enzimas em dietas elaboradas com milho classificado elevou o valor de EMA em comparação à dieta com milho não classificado.

Tabela 4. Custo por $\mathrm{kg}$ de frango de acordo com a qualidade do milho e a inclusão de complexo enzimático

\begin{tabular}{lcccccccc}
\hline & \multicolumn{3}{c}{ MC } & \multicolumn{4}{c}{ MNC } \\
\hline Custo, R $\$ / \mathrm{kg}$ & Controle & CE & CE $\downarrow$ EM & Média & Controle & CE & CE $\downarrow$ EM & Média \\
\cline { 2 - 9 } 0 a 21 dias & 0,99 & 1,00 & 0,95 & 0,98 & 0,93 & 0,94 & 0,88 & 0,91 \\
21 a 42 dias & 1,94 & 1,97 & 1,82 & 1,91 & 1,75 & 1,87 & 1,71 & 1,78 \\
1 a 42 dias & 2,93 & 2,98 & 2,77 & 2,89 & 2,68 & 2,81 & 2,59 & 2,69 \\
\hline
\end{tabular}

CE: complexo enzimático, CE $\downarrow$ EM: complexo enzimático + redução de 150kcal de EM, MC: milho classificado, MNC: milho não classificado.

Quanto à ação das enzimas, Pack et al. (1998) relataram que melhorias na digestibilidade, pela suplementação das enzimas, podem ser atribuídas à degradação da parede celular, que facilita o contato das enzimas endógenas com o substrato a ser digerido, justificando tais resultados.

Comparando-se as dietas com enzima e redução de EM, foi observado um resultado inverso $(\mathrm{P}<0,05)$, ou seja, obteve-se um maior valor de EMA quando as enzimas foram adicionadas às dietas elaboradas com milho não classificado em comparação ao uso de milho classificado. Este resultado pode ser atribuído ao maior "espaço de atuação" das enzimas em dietas elaboradas com milho não classificado, devido à grande variação nutricional e das frações de PNAs e às impurezas presentes nesse ingrediente.

Para a EMAn, também foi observada interação significativa $(\mathrm{P}<0,05)$. Ao se desdobrar a interação, observou-se que, tanto para o milho classificado quanto para o não classificado, os resultados observados foram idênticos aos descritos para a EMA. Na comparação entre milho classificado ou não, observaram-se maiores valores de EMAn para dietas à base de milho não classificado em relação ao uso de milho classificado, com exceção da dieta acrescida de enzimas. Esses resultados podem ser justificados pelo fato de que, em aves em crescimento, a proteína retida no corpo da ave e, consequentemente, não catabolizada até os 


\section{Fernandes et al.}

produtos de excreção nitrogenada, não contribui para a energia das fezes e da urina (Sakomura e Rostagno, 2007). Assim, a utilização de uma dieta de pior qualidade (milho não classificado) resultou em menor ganho de peso (Tab. 3) e na maior excreção de produtos nitrogenados, o que elevou os valores de EMAn em relação à EMA, que não leva em consideração essa retenção.

Tabela 5. Peso relativo de órgãos de frangos de corte aos 21 dias de idade recebendo dietas elaboradas com milho classificado ou não e suplementadas ou não com enzima em dietas com redução ou não da energia metabolizável

\begin{tabular}{|c|c|c|c|c|c|c|c|c|c|c|c|c|c|c|c|}
\hline & \multicolumn{3}{|c|}{ Moela } & \multicolumn{3}{|c|}{ Pâncreas } & \multicolumn{3}{|c|}{ Pró-ventrículo } & \multicolumn{3}{|c|}{ Intestino } & \multicolumn{3}{|c|}{ Figado } \\
\hline & $\mathrm{MC}$ & MNC & Média & $\mathrm{MC}$ & MNC & Média & MC & MNC & Média & $\mathrm{MC}$ & MNC & Média & MC & MNC & Média \\
\hline Tratamentos & & & & & & & & & & & & & & & \\
\hline Controle & 3,95 & 4,09 & $4,02^{\mathrm{A}}$ & 0,30 & 0,28 & $0,29^{\mathrm{B}}$ & 0,53 & 0,54 & 0,53 & 5,37 & 5,26 & 5,31 & 2,51 & 2,51 & $2,51^{\mathrm{B}}$ \\
\hline $\mathrm{CE}$ & 3,78 & 3,75 & $3,77^{\mathrm{AB}}$ & 0,31 & 0,30 & $0,30^{\mathrm{AB}}$ & 0,52 & 0,54 & 0,53 & 5,57 & 5,25 & 5,41 & 2,73 & 2,61 & $2,67^{\mathrm{AB}}$ \\
\hline CE $\downarrow E M$ & 3,56 & 3,85 & $3,70^{\mathrm{B}}$ & 0,31 & 0,34 & $0,33^{\mathrm{A}}$ & 0,50 & 0,56 & 0,53 & 5,24 & 5,85 & 5,55 & 2,65 & 2,80 & $2,72^{\mathrm{A}}$ \\
\hline Média & 3,76 & 3,90 & & 0,31 & 0.31 & & $0,52^{\mathrm{b}}$ & $0,54^{\mathrm{a}}$ & & 5,39 & 5,45 & & 2,63 & 2,64 & \\
\hline CV, \% & & 10,96 & & & 14,63 & & & 11,12 & & & 16,05 & & & 11,73 & \\
\hline Interação & & NS & & & NS & & & NS & & & NS & & & NS & \\
\hline
\end{tabular}

CE: complexo enzimático, CE $\downarrow$ EM: complexo enzimático + redução de $150 \mathrm{kcal}$ de EM, MC: milho classificado, MNC: milho não classificado. *Médias seguidas de letras distintas maiúsculas na coluna diferem entre si pelo teste de Tukey...Médias seguidas de letras minúsculas distintas na linha diferem entre si pelo teste de Tukey.

Tabela 6. Morfometria intestinal de frangos de corte aos 21 dias de idade recebendo dietas elaboradas com milho classificado ou não e suplementadas ou não com enzima em dietas com redução ou não da energia metabolizável

\begin{tabular}{|c|c|c|c|c|c|c|c|c|c|c|c|c|}
\hline & \multicolumn{6}{|c|}{ Duodeno } & \multicolumn{6}{|c|}{ Jejuno } \\
\hline & \multicolumn{3}{|c|}{ Vilo, $\mu \mathrm{m}$} & \multicolumn{3}{|c|}{ Cripta, $\mu \mathrm{m}$} & \multicolumn{3}{|c|}{ Vilo, $\mu \mathrm{m}$} & \multicolumn{3}{|c|}{ Cripta, $\mu \mathrm{m}$} \\
\hline Tratamentos & & & & & & & & & & & & \\
\hline $\mathrm{CE}$ & 1286,2 & 1305,8 & 1298,0 & 196,7 & 176,1 & 184,4 & 895,3 & 953,1 & 926,8 & 138,49 & 150,56 & 145,07 \\
\hline $\mathrm{CE} \downarrow \mathrm{EM}$ & 1333,3 & 1169,1 & 1251,2 & 158,2 & 155,9 & 157,1 & 738,3 & 799,2 & 766,0 & 116,52 & 142,85 & 127,05 \\
\hline Média & 1369,9 & 1265,2 & & 167,39 & 167,5 & & 791,9 & 895,6 & & 127,64 & 144,93 & \\
\hline
\end{tabular}

CE: complexo enzimático, CE $\downarrow$ EM: complexo enzimático + redução de 150kcal de EM, MC: milho classificado, MNC: milho não classificado.

Tabela 7. Coeficientes de digestibilidade da matéria seca (CDMS), da proteína bruta (CDPB) e do extrato etéreo (CDEE) de dietas elaboradas com milho classificado ou não e suplementadas ou não com enzima em dietas com redução ou não da energia metabolizável

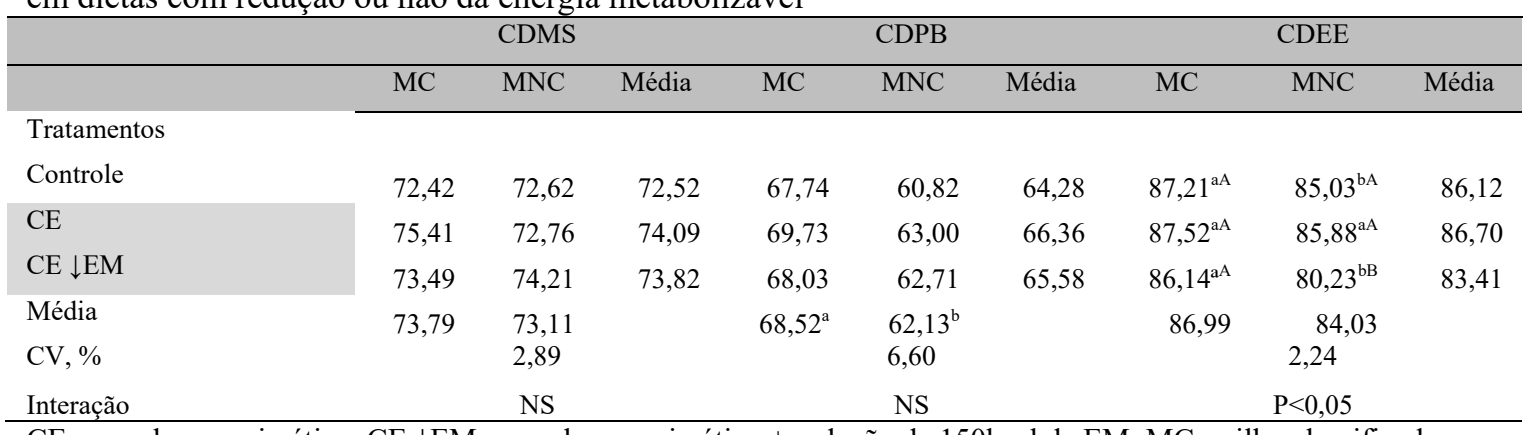

CE: complexo enzimático, CE $\downarrow$ EM: complexo enzimático + redução de 150kcal de EM, MC: milho classificado, MNC: milho não classificado. *Médias seguidas de letras distintas maiúsculas na coluna diferem entre si pelo teste de Tukey. Médias seguidas de letras minúsculas distintas na linha diferem entre si pelo teste de Tukey. 
Tabela 8. Valores de energia metabolizável aparente (EMA) e energia metabolizável aparente corrigida para balanço de nitrogênio (EMAn) de dietas elaboradas com milho classificado ou não e suplementadas ou não com enzima em dietas com redução ou não da energia metabolizável

\begin{tabular}{lcccccc}
\multicolumn{5}{c}{ EMA } & \multicolumn{3}{c}{ EMAn } \\
\hline Tratamentos & MC & MNC & Média & MC & MNC & Média \\
\cline { 2 - 7 } Controle & & & & & \\
CE & $3614,81^{\mathrm{aB}}$ & $3538,26^{\mathrm{aA}}$ & 3576,54 & $2975,46^{\mathrm{bB}}$ & $3262,69^{\mathrm{aA}}$ & 3128,65 \\
CE $\downarrow$ EM & $3748,09^{\mathrm{aA}}$ & $3559,48^{\mathrm{bA}}$ & 3653,79 & $3235,26^{\mathrm{aA}}$ & $3218,65^{\mathrm{aA}}$ & 3227,51 \\
Média & $3395,04^{\mathrm{bC}}$ & $3522,47^{\mathrm{aA}}$ & 3453,85 & $3044,06^{\mathrm{bB}}$ & $3199,97^{\mathrm{aA}}$ & 3109,02 \\
CV, \% & 3594,28 & 3541,67 & & 3091,76 & 3231,59 & \\
Interação & & 2,41 & & & 4,39 & \\
\hline
\end{tabular}

CE: complexo enzimático, CE $\downarrow$ EM: complexo enzimático + redução de 150kcal de EM, MC: milho classificado, MNC: milho não classificado. *Médias seguidas de letras distintas maiúsculas na coluna diferem entre si pelo teste de Tukey. Médias seguidas de letras minúsculas distintas na linha diferem entre si pelo teste de Tukey.

O complexo enzimático adicionado às dietas elaboradas com milho classificado, em relação às dietas com milho não classificado, melhorou a EMA e a EMAn das aves, semelhantemente aos resultados encontrados por Slominski (2011), que observou melhora na EMAn quando utilizou enzimas exógenas em dietas à base de milho, $\mathrm{e}$ contrariando os resultados de Cowieson e Adeola (2005), que não encontraram nenhum efeito significativo ao usarem enzima para melhorar a EMAn.

O gerenciamento das decisões baseado no custobenefício da separação do milho em mesas gravimétricas deve levar em conta também situações de desafios sanitários e ambientais, como altas temperaturas e níveis de amônia na cama observados em criações comerciais. Em condições experimentais, os desafios naturais são mínimos, fazendo com que os animais tenham condições de manter o desempenho produtivo, mesmo quando os ingredientes da dieta não atendem aos requisitos de qualidade. Outro fator a ser considerado é a presença de grãos quebrados, ardidos e impurezas que contribuem para o aumento dos níveis de micotoxina. Quando há interações com micotoxinas, as decisões sempre serão muito mais difíceis, vistas as múltiplas consequências sobre o crescimento $\mathrm{e}$ a sanidade das aves.

A inclusão de complexos enzimáticos na dieta das aves pode ser uma questão de oportunidade de negócio para as empresas, visando diminuir os custos de produção. A avaliação econômica das dietas deve ser uma ferramenta de rotina, uma vez que o custo e a qualidade do milho, principal ingrediente em volume, podem sofrer flutuações sazonais ao longo do ano, o que pode interferir diretamente nos resultados tanto produtivos quanto econômicos.

Alguns resultados ainda são controversos, sobretudo porque existem diferenças quanto à presença de substratos nas dietas, à composição dos ingredientes, às metodologias utilizadas na avaliação dos resultados e à coleta de dados, bem como quanto às diferenças na atividade enzimática de cada produto. Assim, todos os aspectos devem ser considerados para uma correta utilização das ferramentas disponíveis, a fim de que resultados expressivos possam ser obtidos mediante a utilização de enzimas apropriadas e que possuam estabilidade e eficácia comprovadas.

\section{CONCLUSÕES}

As aves suplementadas com enzima, independentemente da classificação do milho, apresentaram maior ganho de peso na fase inicial. A associação de milho classificado e a inclusão de enzimas resultaram na melhor conversão alimentar. $\mathrm{O}$ custo $/ \mathrm{kg}$ de frango produzido foi menor em dietas elaboradas com milho não classificado independentemente do uso de enzima. O CDPB foi maior para dietas elaboradas com milho classificado, independentemente da suplementação do complexo enzimático, enquanto o CDEE de dietas à base de milho não classificado aumentou quando as enzimas foram incluídas na dieta. Dietas elaboradas à base de milho classificado e acrescidas de complexo enzimático comercial melhoraram a EMA e a EMAn. 


\section{Fernandes et al.}

\section{REFERÊNCIAS}

AGUILAR, L.; DELGADO, G.; BUENO, G.; RODRIGUEZ-LÉON, J.A. Enzyme application in animal feeding: requirements and perspectives. Rev. Cub. Cienc. Avic., v.31, p.45-55, 2007.

AO, T.; CANTOR, A.H.; PESCATORE, A.J. et al. Effect of enzyme supplementation and acidification of diets on nutrient digestibility and growth performance of broiler chicks. Poult. Sci., v.88, p.111-117, 2009.

BAIDOO, S.K.; SHIRES, A.; ROBBLEE, A.R. Effect of kernel density on the apparent and true metabolizable energy value of corn for chickens. Poult. Sci., v.70, p.2102-2107, 1991.

COSTA LEITE, P.R.; LEANDRO, N.S.M.; STRINGHINI, J.H. et al. Desempenho de frangos de corte e digestibilidade de rações com sorgo ou milheto e complexo enzimático. Pesqui. Agropec. Bras., v.46, p.280-286, 2011.

COSTA, F.G.P.; CLEMENTINO, R.H.; JÁCOME, I.M.T.D. et al. Utilização de um complexo multienzimático em dietas de frangos de corte. Rev. Ciênc. Anim. Bras., v.5, p.63-71, 2004.

COWIESON, A.J.; ADEOLA, O. Carbohydrases, protease, and phytase have an additive beneficial effect in nutritionally marginal diets for broiler chicks. Poult. Sci., v.84, p.1860-1867, 2005.

COWIESON, A.J.; BEDFORD, M.R.; RAVINDRAN, $\mathrm{V}$. Interactions between xylanase and glucanase in maize-soy-based diets for broilers. Br. Poult. Sci., v.51, p.246-257, 2010.

LIMA, F.R. Aditivos zootécnicos: enzimas. In: PALERMO NETO, J.; SPINOSA, H.S.; GÓRNIAK, S.L. (Eds.). Farmacologia aplicada à avicultura. São Paulo: Roca, 2005. p.239-248.

MALATHI, V.; DEVEGOWDA, G. In vitro evaluation of nonstarch polysaccharide digestibility of feed ingredients by enzymes. Poult. Sci., v.80, p.302305,2001

MALLMANN, C.A.; DILKIN, P.; RAUBER, R.H. Micotoxinas e micotoxicoses na avicultura. In: BERCHIERI, A.J.; SILVA, E.N.; DI FABIO, J. et al. (Eds.). Doença das aves. Campinas: FACTA, 2009. p.821-832.

MAZZUCO, H.; LORINI, I.; BRUM, P.A.R. Composição química e energética do milho com diversos níveis de umidade e diferentes temperaturas de secagem para frangos de corte. Rev. Bras. Zootec., v.31, p.2216-2220, 2002.

MATTERSON, L.D.; POTTER, L.M.; STUTZ, M.W. The metabolizable energy of feed ingredients for chickens. Storrs: University of Connecticut, Agricultural Experiment Station, 1965. 11p.

MERONUCK, R.A. The significance of fungi in cereal grains. Plant Dis., v.71, p.287-291, 1987.
OFFICIAL methods of analysis. 16.ed. Washington: AOAC, 1995. 1137p

PACK, M.; BEDFORD, M.; WYATT, C. Feed enzymes may improve corn, sorghum diets. Feedstuffs, v.70, p.18-19, 1998.

RODRIGUES, P.B.; ROSTAGNO, H.S.; ALBINO, L.F.T. et al. Desempenho de frangos de corte, digestibilidade de nutrientes e valores energéticos de rações formuladas com vários milhos, suplementadas com enzimas. Rev. Bras. Zootec., v.32, p.171-182, 2003

ROSTAGNO, H.S.; ALBINO, L.F.T.; DONZELE, J.L. et al. Tabelas brasileiras para aves e suínos: composição de alimentos e exigências nutricionais de aves e suínos. 3.ed.Viçosa: UFV, 2011. 252 p

RUFATTO, S.; CORREA, P.C.; MARTINS, J.H. et al. Efeito das condições de colheita, préprocessamento e armazenamento na qualidade do milho-pipoca. Pesqui. Agropec. Bras, v.35, p.591-597, 2000.

SAKOMURA, N.K.; ROSTAGNO, H.S. Métodos de pesquisa em nutrição de monogástricos. Jaboticabal: FUNEP, 2007. p.283

SAS Institute Inc. 2002. Software and services: system for Windows, version 8.0 software Cary.

SILVA, C.S.; MENTEN, J.F.M.; TRALDI, A.B. et al. Avaliação de milhos de diferentes densidades para frangos de corte. Rev. Bras. Zootec., v.40, p.15541561, 2011.

SILVA, C.S.; COUTO, H.P.; FERREIRA, R.A. et al.Valores nutricionais de milhos de diferentes qualidades para frangos de corte. Rev. Bras. Zootec., v.37, p.883-889, 2008.

SLOMINSKI, B.A. Recent advances in research on enzymes for poultry diets. Poult. Sci., v.90, p.20132023, 2011.

SORBARA, J.O.B.; MURAKAMI, A.E.; NAKAGE, E.S. et al. H. Enzymatic programs for broilers. Braz. Arch. Biol. Technol., v.52, p.233-240, 2009.

STRADA, E.S.O.; ABREU, R.D.; OLIVEIRA, G.J.C. et al. Uso de enzimas na alimentação de frangos de Corte. Rev. Bras. Zootec., v.34, p.2369-2375, 2005.

YU, B.; CHUNG, T.K. Effects of multiple-enzyme mixtures on growth performance of broilers fed cornsoya meal diets. J. Appl. Poult. Res., v.13, p.178-182, 2004.

ZANELLA, I.; SAKOMURA, N.K.; SILVERSIDES, F.G. et al. Effect of enzyme supplementation of broiler diets based on corn and soybeans. Poult. Sci., v.78, p.561-568, 1999

ZAVIEZO, D.; CONTRERAS, M. Impacto de hongos y micotoxinas en las aves. Rev. Ind. Avíc., v.52, p.19-22, 2005. 